\title{
Applying Triz for Production Quality Improvement
}

\author{
Nikalus Shu Luing Swee ${ }^{1}$, Guat Guan Toh ${ }^{2}$, Mum Wai Yip ${ }^{3}$, Chee Sheng Keong ${ }^{4}$ and See Chew Tai ${ }^{5}$ \\ ${ }^{1}$ Tunku Abdul Rahman University College, Department of Computer Science and Mathematics, Malaysia \\ ${ }^{2}$ Tunku Abdul Rahman University College, Deputy Branch Campus Head, Malaysia \\ ${ }^{3}$ Tunku Abdul Rahman University College, Department of Mechanical Engineering, Malaysia \\ ${ }^{4}$ Tunku Abdul Rahman University College, Centre of Pre-University Studies, Malaysia \\ ${ }^{5}$ Tunku Abdul Rahman University College, Department of Electronic Engineering, Malaysia
}

\begin{abstract}
This paper aims to provide a thorough analysis on the application of TRIZ in improving the quality of canned food production. TRIZ tools such as engineering systems analysis, function analysis, cause and effect chain analysis, By-separation model and 40 Inventive Principles are applied in order to discover some feasible and elegant solutions to alleviate the problem. Findings revealed that the rejected canned products on the conveyor belt will be isolated or picked up with other good condition canned products which are lined up very closely to the rejected cans; though the visioning system is able detect the fault printing on the canned product. The main root cause is that the rejected canned product is picked up with other canned products in good condition because all cans are lined up on the belt and are very close to each other or having no gaps between the cans. Conversely, all cans on the conveyor belts are required to be very close to each other to avoid collisions that may damage the cans. The root cause is solved by applying function analysis, By-separation tool and Inventive Principles. Therefore, it can be concluded that TRIZ is a powerful tool in inventive problem solving.
\end{abstract}

\section{Introduction}

Production lines comprise of a set of sequential processes whereby materials are out through a refining operation to produce an end-product that is suitable for consumer market; or components that are assembled to make finished product [1]. It also includes inspecting, labeling, and packing the final product before the product is released.[2] Equipments, materials and human resources influence the reliability and capacity of the production operation. Therefore, identifying bottleneck resources and employing an effective scheduling structure for the production process were critical. [2]. Production line commonly is equipped with a belt conveyor system. A belt conveyor system consists of more than 2 pulleys, with endless loop of transporting products or materials. With respect to the forecasts and plans, the expected multitude of options are being developed in order to meet the demand of an industry requiring ever more complex devices which exhibit higher reliability, speedy production and lower cost [3-4]. There are challenges in handling production process. The production technologies need to be aware of the issues of downstream handling, especially loading and unloading of goods, and transportation by all channels [4]. The production applications commonly include visionguidance of high-speed robots in product packing with simultaneous rejection of substandard items, robotic fishfilleting, color-sorting and grading of capsicum peppers, counting glass anesthesia vials in a tray, and detecting the tracks on the circuit board in a medical device. Many of the applications concerned traceability: for example, checking the presence and readability of date codes and bar codes on product packaging, and checking the labeling and etc. [5].

TRIZ is a Russian acronym for "Teoriya Resheniya Izobreatatelskikh Zadatch", equivalent to "Theory of Inventive Problem Solving" in English. TRIZ methodology was founded in 1940's by Genrich Altshuller and his team. He was an inventor, a writer and a patent engineer who studied intellectual property contained in approximately 200,000 patents [6]. He discovered and organized his study of 40,000 patents according to innovative patterns of design as well as the inventive principles in these innovative solutions. Findings revealed that problems and solutions, patterns of technical evolution were repeated across industries and sciences, and innovations used scientific effects outside the field where they were developed. Therefore, Genrich Altshuller derived 40 inventive principles [6-13]. TRIZ comprises of several essential tools such as engineering systems analysis, function analysis, cause and effect chain analysis, trimming, engineering contradiction, byseparation, substance-field model, Trends of Engineering System Evolutions, ARIZ, and etc. TRIZ uses 40 inventive principles and 39 parameters to help inventors to derive many solutions [6-13].

\section{Problem statement}


Direct observation revealed that the rejected canned products on the conveyor belt will be picked up with other good condition canned products which are lined up very closely to the rejected cans; though the visioning system is able detect the fault printing on the canned product. If the rejected cans are lined up with other cans without gaps (adjacent to each other very closely), the good condition canned products before and after the rejected canned product will be picked up together.

There are a few constraints to be taken into account such as the speed of the conveyor and the level of the conveyor cannot be altered, and the material of the belt cannot be changed. No budget for sophisticated solutions such as robotic arms. The following are the details on how TRIZ is applied in this case study.

\section{Triz models and tools}

TRIZ flow process is shown in Figure 1. First and foremost, research and brainstorming help identify the original problem to resolve, and this is followed by function analysis, cause and effect chain analysis, and Physical contradiction. Finally, By-Separation strategy is applied to derive specific inventive principles and specific solution(s) [6-7].

- Research \& Brainstorming
(Space, Time, Relation, System
level)

Figure 1. Flow of TRIZ processes.

\subsection{Engineering system definition}

An Engineering System consists of several components that are interacted among each other. These components are commonly accepted as system components (subsystems) that are listed in Table 1. Along with subsystems, there are also interactions between engineering system and external entities called supersystems. Supersystems are not designed as part of the Engineering System; however, they can influence the Engineering System [6-7].

Table 1. Engineering system.

\begin{tabular}{|l|l|}
\hline $\begin{array}{l}\text { Sub/System } \\
\text { Components }\end{array}$ & $\begin{array}{l}\text { visioning system, canned product, } \\
\text { conveyor belt, guided track, conveyor } \\
\text { frame, conveyor tripod, motor, pulley }\end{array}$ \\
\hline Supersystems & $\begin{array}{l}\text { air particles/dust, workers, freight, } \\
\text { Humidity, Ambient Thermal }\end{array}$ \\
\hline
\end{tabular}

\subsection{Function analysis}

Function analysis shows the interactions between two or more systems/subsystems (Engineering System components) which are listed in Figure 2. These interactions are called functions. Functions are simply actions between two components, i.e., a subject and an object in which the subject acts upon and modifies a parameter(s) of the object [6]. Two main types of functions are useful function and harmful function. As for useful function, it comprises of "normal", "insufficient", and "excessive" functions. [6-7].

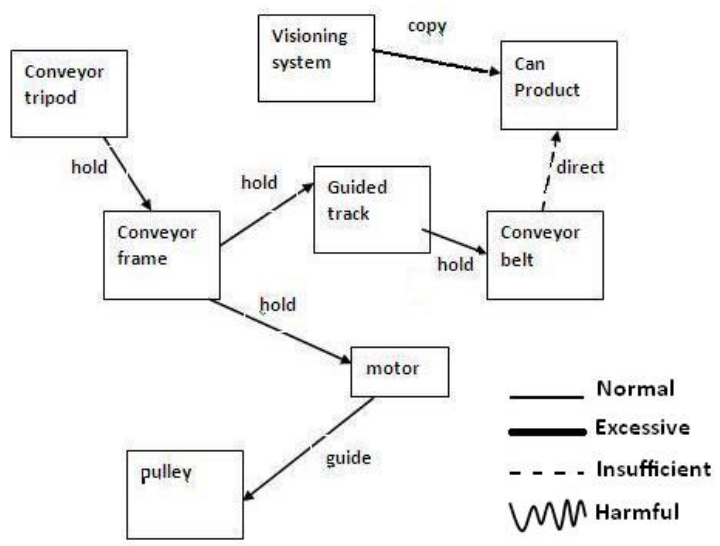

Figure 2. Function model.

\subsection{Cause and effect chain analysis (CECA)}

The following stage is Cause and Effect Chain Analysis(CECA). CECA is a crucial tool in the TRIZ methodology. It helps identify the right root cause(s) pertaining to the problem in Figure 3. If the wrong root cause is derived, it leads to ineffective solution. Fundamentally, CECA is very similar to "5 Whys". We prompt for causes continuously for the problem from high level causes to low level causes by asking "the question "why?" [6].

From the CECA, the root cause identified is that the canned goods are lined up very closely or even without gaps on the conveyor to prevent collisions among the cans. However, the adjacent good condition canned goods before and after the rejected canned goods will be picked up together.

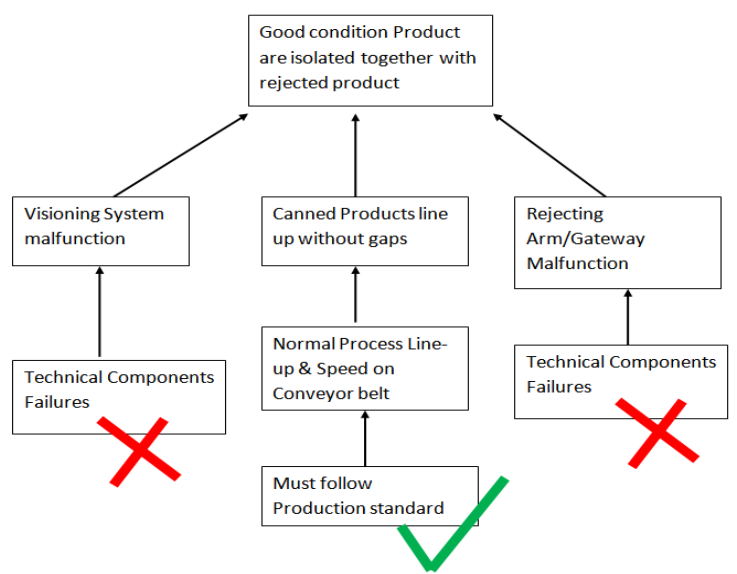

Figure 3. Cause and Effect Chain Analysis Diagram. 


\subsection{Physical contradiction}

Physical Contradiction of an engineering system refers to the presence of a contradiction in an engineering system involving a single parameter (e.g. area, length, volume, etc.) which has a contradiction at two different values. [67]. For example, an airplane wing needs to have large surface for easy takeoff and small surface for fast speeds. Airplane landing gear needs to be present during landing but does not need to be present during flight to reduce wind resistance. The essence of the Physical Contradiction is to find the controlling characteristic. The Physical Contradiction can be solved through methods such By-Separation in (Space, Time, Relation, System level) and By-Satisfaction, and Bypass. In this case study, we employ By-Separation model.

Based on the case study, the following Physical Contradiction is proposed.

- Canned goods need to be separated (with noticeable gaps) in order to be picked up individually if found containing printing error.

- Canned goods need to be very close to each other (with no gaps) to avoid collisions which may damage the cans.

\subsection{TRIZ tools: By Separation (space, time, relation, system level)}

To determine whether the Separation can be done in Space, in Time, or in Relation, the following scenarios should be established [6]:

-Separation in Space - Where do I need condition A? Where do I need condition -A?

-Separation in Time - When do I need condition A? When do I need condition -A?

-Separation in Relation - I need condition A IF ? I need condition -A IF?

-Separation in System level - The Physical Contradiction's controlling parameter has a value at the system level but has an opposite value at the component level or a controlling parameter exists at the system level but not at the component level.

During operation time analysis, let's define the following variables: T1(Time during visioning system), T2 (Time during rejecting process), T3 (Time after rejecting process). During T1, all cans move in a normal speed and are adjacent to each other without gaps towards the visioning system to detect any printing errors on the cans and to avoid collisions. The visioning system is able to detect the all printing errors effectively.

During T2, after leaving the visioning system section and reach the rejecting arm/gateway, all cans should be separated (with noticeable gaps) to allow rejection of individual defective can accurately without pulling in any good condition cans.

During T3, all "Pass-QA" canned goods will continue to drift the next production section.
Hence, based on the operation time analysis, Separation In Time strategy is suitable for the problem. There are many recommendations of Inventive principles in Separation in Time [6], only Inventive principles \#10 Prior Action, Inventive principles, \#15 Dynamization, Inventive principles \#16 Partial and Excessive Action, Inventive principles \#19 Periodic Action are deemed suitable for the problem after thorough discussion with production engineers.

\section{TRIZ solutions and discussion}

\subsection{Solution derived by Inventive Principle \#10 Prior action and \#15 Dynamization}

Referring to the proposed inventive principles above, Inventive Principle \#10 Prior action suggests prearranging objects such that they can come into action from the most convenient place without losing time. Inventive principles \#15 Dynamization suggests to divide an object into parts capable of movement relative to each other. Based on the suggested Inventive principles, production engineers can install rubbers with spring rods on the conveyor before the visioning system and also before the rejecting arm to separate the cans. The rubber rods/arms act as a diverter gate/arm to separate the cans with acceptable range of gap to avoid serious collisions among the cans 14].

\subsection{Solution derived by inventive principle \#19 periodic action and \#16 partial or excessive action}

Inventive principles \# 16 Partial or Excessive Action suggests that if the finished product is hard to achieve using a given solution method then, use "slightly less" or "slightly more" of the similar method. Inventive Principle \#19 Periodic Action suggests to use pulsating actions to change the situation. Based on suggested Inventive principles, production engineers can install vacuum suction cup to separate the canned goods upon passing the sensors. Suction cup will be activated and controlled by the sensors on the conveyor belt periodically to delay the movement of cans in order to have gaps between cans [15]. Hence, the rejected cans can be diverted to the rejection gateway. The suction strength is needed to be optimized for the best solution in relation to the weight of the cans.

\section{Conclusion}

The ever improving technology in production line should be able to handle any sizes of products in a speedy, reliable, and cheaper cost [3-4]. In this case study, the problem can be contained and lessened by applying TRIZ tools particularly the Physical Contradiction and BySeparation tools. TRIZ helps engineers generate more feasible ideas or concepts which may lead to elegant solutions. 
TRIZ requires an active cooperation between field specialists and TRIZ consultant so as to find the right root causes and derive ideas or effective solutions. It can be concluded that TRIZ is a systematic and an innovative problem solving methodology.

\section{References}

1. Sarder, MD Baniamin; Liles, Don H; Ali, M Yousuf. Design \& Implementation of production line in apparel manufacturing industry IIE Annual Conference. Proceedings : 1-6 (2005)

2. U. Michael, G. Van, U. Elisabeth, Improving production line performance, IIE Solutions; Nov ; 32, 11; ProQuest, pg. 36 (2000)

3. Andy Longford, Chip packaging challenges . . . a roadmap based overview, Microelectronics International, 22/2, 17-20 (2005)

4. Lagner, P., Advantest Handling challenges of small $\&$ fine pitch devices, Advantest Technical Forum, January (2004)

5. Christine Connolly, Sensor trends in processing and packaging of foods and pharmaceuticals, 27/2 103108 (2007)

6. T.S. Yeoh, T.J. Yeoh, and C.L. Song, TRIZSystematic Innovation in Manufacturing, Selangor: Firstfruits (2009)
7. A.A. Guin, A.V. Kudryavtsev, V. Yu. Boubentsov, A. Seredinsky, Theory of Inventive Problem Solving, First Fruits (2009)

8. D. Mann, Hands-On Systematic Innovation. Belgium: CREAX Press (2003)

9. D. Mann, Hands-On Systematic Innovation for Business and Management, Devon: Lazarus Press (2007)

10. E. M. Smith, From Russia with TRIZ, Mechanical Engineering, 125, 3; Academic Research Library, pp. D18, Mar (2003)

11. G.S. Altshuller, The Innovation Algorithm, TRIZ Systematic Innovation and Technical Creativity, Worcester, MA: Technical Innovation Centre (2000)

12. G.S. Altshuller, 40 Principles, TRIZ Keys to Technical Innovation, Worcester, MA: Technical Innovation Centre (2002)

13. J. Terninko, A. Zusman, and B. Zlotin, Systematic Innovation: An Introduction to TRIZ. New York, NY: CRC Press (2010)

14. F. J. Minner, Plastic conveyor-belt fasteners eliminate scratched parts, Quality; 34, 4; ProQuest Science Journals, pg. 138 (1995)

15. Zalud, Todd, Using suction cups to design a vacuum system, Machine Design; Dec 10; 70, 22; pg. 114 (1998) 